\title{
Between the heritage and the contemporaneity of the industrial city of Alcoy
}

\author{
Maite Palomares Figueres, Ciro Vidal Climent, Ivo Vidal Climent
}

Escuela Técnica Superior de Arquitectura, Universitat Politècnica de València. Valencia, Spain

E-mail:mapafi@upv.es, civicli@pra.upv.es,ivvicli@pra.upv.es

\begin{abstract}
The ARA plan, acronym for Architecture and Rehabilitation of Alcoy, was the response to a collective desire of change and to the need for the renewal of an industrial city with a deeply rooted bourgeois and working-class base. The impulse and credibility that made possible the conception of the ARA plan came from a series of projects that consolidated seriously damaged zones of the historic center, and secondarily from the economic commitment of the Generalitat with urban projects of great disciplinary interest that, at that time, had the character of pioneers for their modern procedures of intervention on the inherited city. The common framework of Plan ARA hosted many urban proposals very different in their methodology. However the sense of their cohesion in the city was evident because behind them there was a thought of order necessary for the consolidation and modernization of the urban patrimony that future challenges would ask for. The most relevant architectural project was the renovation of the neighborhood of La Sang, which won the FAD Architecture Award in 1999, but for the citizens the evidence of a remarkable change came with the construction of the public parks. Since that moment the people perceived that an ambitious and clear idea of the city was giving shape to their daily domestic outer spaces. Unfortunately a mix of political and economical issues truncated or set aside important ongoing projects so the completion of the ARA plan was never reached and the aspiration of becoming a strategic city was forgotten.
\end{abstract}

Keywords: City renewal, urban patrimony, industrial city, heritage modernization

\section{The awakening of a town}

Alcoy is an industrial city that flourished in the nineteenth century with the increase of working class population and the construction of a set of bridges that established a service plan in order to eliminate the limitation of its topography. Its urban structure is made up of a medieval historical part with its menestral inheritance, two nineteenth-century extensions and a dispersed industrial infrastructure in these two extensions as well as along the rivers. The city has a factory worker base, an industrial bourgeoisie and a petty bourgeoisie that prefers the business of trading rather than the effort of production.

The ARA plan of Alcoy was the project of the collective desires of a city that wanted to awaken and thrive from the lethargy imposed by history to an autonomous position within the province of Alicante, like a Greek polis. Architecture and Rehabilitation of Alcoy baptized an acronym covered with a desire for affirmation, because it had to be 'ara' (now) the right instant, the expected moment that no longer would postpone to show the quality of its heritage and its renewed impetus.

During the democratic transition in September 1978, the public baths belonging to the Monte de Piedad are demolished. They were a property annexed to the recently demolished house of Beneficencia and inheritance of the workers' past, but the destruction is perceived as an act of barbarism associated with the 
mercantile value of the lot and not of the building. This new criteria of the institutions in front of the historical remains alerted about the defenselessness of the city's heritage and, in a way, it was the trigger that pushed the new mayor of the city in the 1979 elections, Mr. Jose Sanus Tormo, to assume the role of guardian of the city and become aware of the need to value and invigorate its urban qualities.

After the first democratic elections, an alliance was established between the power of management, personified in the political figure of the mayor, and the power of thought and action present in the architect Vicente Vidal. Both are aware of the historical opportunity of intervention on the city and look for models of intervention in historic centers in Europe.

This inquiry leads them to Italy during Easter 1979. There, architect Pier Luigi Cervellati shows them the political action and methodology of intervention in the historic center of Bologna, whose vitality is explained by a strong industrial establishment in its urban area, where the different social forces and their various interests are added to the general problem of the housing sector in the city, of which the historical center is a particular case. On the one hand, the interest of citizens to live differently and at lower prices under a citizen organization that responds to their social needs. On the other there are the interests of real estate capital that tend to a growing accumulation based on speculation. As a solution to these imbalances only public intervention can curb speculative tendencies by forcing private construction to lower or moderate their prices.

The first rehabilitation was carried out in 1982 on the ensemble of Plaza de España and Plaza Mayor promoted by the Ministry of Culture with an aproximate budget of 400.000 $€$. This job was initially commissioned to Rafael Moneo but he declined the offer in favor of Vicente Manuel Vidal Vidal who had his professional office in Alcoy. With the massiveness that needs a square linked to the gunpowder ritual celebrated during the local festivity of Saint George, the project resized and paved the plaza, the sidewalks and the streets while giving a new layout to the central surface that put together the Calderon theater, the cafes, bars and the City Hall. It also introduced a line of seven oaks that end in a small old source and recovered the cobblestones hidden under layers of asphalt. The square was finished with a modest hydraulic motif whose intention was to recall the industrial origins of the city.

For the Plaza Mayor, the annexed volumes that occupied the space of the square were removed and the deteriorated ashlar arches were remade using the same local stone in order to have the same degree of oxidation and coloration. It was a way of recognizing the ethics of the material and the trade to avoid pastiche and to give solidity to the facades. For its illumination, and with the vocation of being a public hall due to its restrained dimensions and volumetric proportion, four luminaries were placed hunging in the intersection of their respective catenaries.

This first work was felt by many inhabitants as the transition from a state of abandonment in a damaged city to a situation of change brought by democracy in which the sense of the public property was felt as something for oneself but usable by all.

As a first test for the green areas needed in the peripheral areas there was a first budget of $200.000 €$ for the park in the North area of the city. An outdoor amphitheater was built emptying a ravine filled with rubble and, above it, a modest bridge gave continuity to the two streets separated by the ravine already clean of debris and carefully landscaped

Two sectors of municipal property almost in ruin, the Fraga tower in Buidaoli and the Barbican in the Raval Vell were the ideal places to try the procedure collected in Bologna against the deterioration of the city. The IVVSA comissioned Vicente Manuel Vidal Vidal and Luis Alonso de Armiño Pérez (both professors of the Polytechnic University of Valencia) the rehabilitation of those zones with a program of social housing. The completion of this works definitively helped to forge the credibility of architecture in its role of renewing the historical fabric of the city.

Barbican street is formed by the buildings that used the outside face of the rammed earth wall 2.7 meters width as the supporting wall. Over time, in an operation that hybridized walls and buildings, its users excavated the wall to get the hygienist complements lacking in the working-class dwellings. Consequently, when defense was no longer necessary, the 


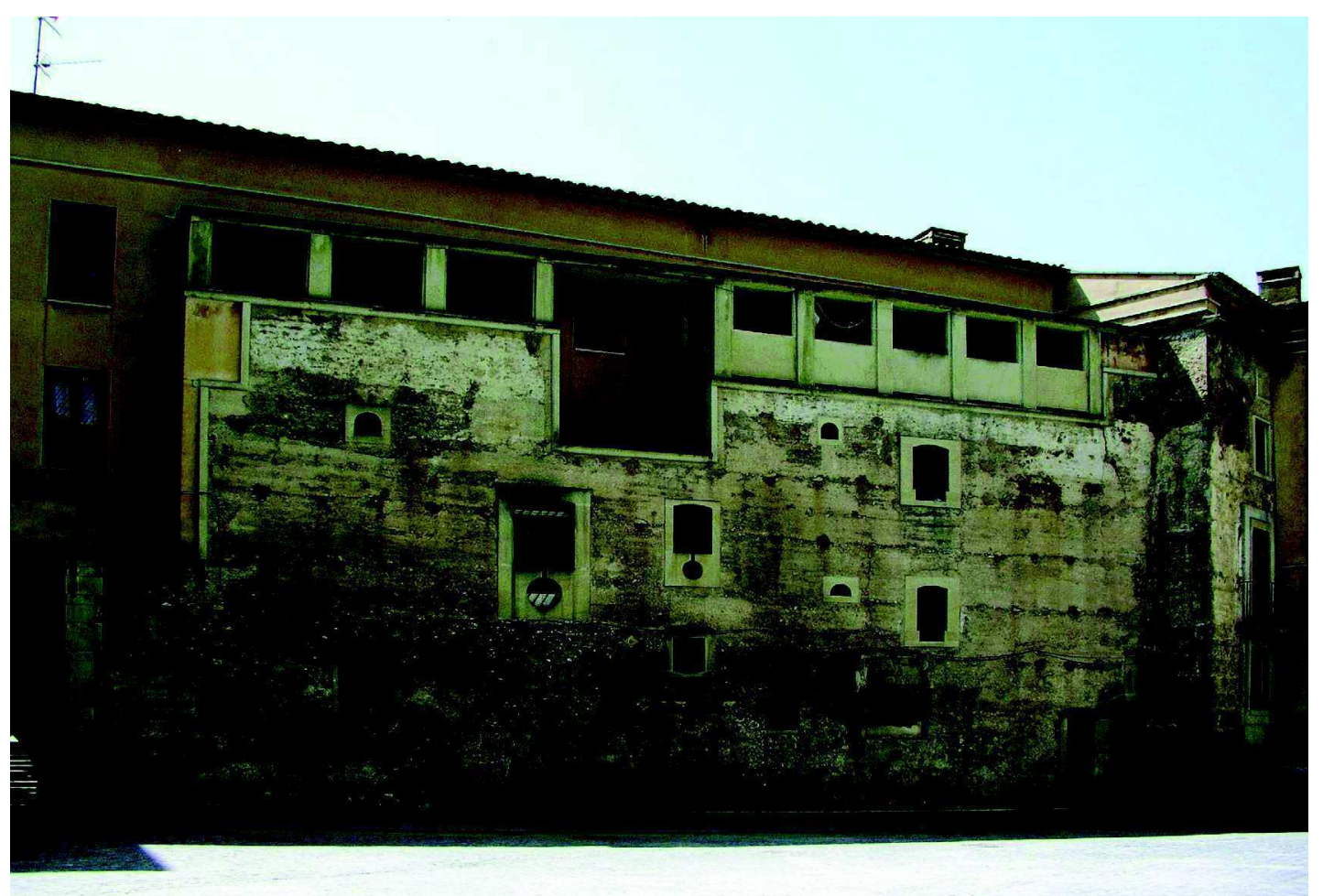

Figure 1.

North facade of the barbican wall of Alcoy. @VVV

wall had to be maintained as it had associated a relevant domestic use of bathrooms and kitchens. In this intervention it would have been easier, for practical reasons, to replace the houses rather than to restore them to a current domestic program, but for historical reasons it was important to keep the wall so, as a kind of payback, the wall protected the houses attached to it (figure 1).

As for the institutional program the building of the Bank of Spain was transformed into a Culture house. It is a neoclassical building made by the academic Luis Menéndez Pidal with drawings whose copies in 1/66 scale detail the whole stonework of the facade. The authority that confers this level of precision avoided the temptation of manipulating it. So the building welcomed the program of a house of culture without giving up the urban character consolidated during its permanence. The project was carried out by Vicente Vidal Vidal with Rafael Silvestre García as a local collaborator.

Anotherwork that kept the life of an institution with high volumetric autonomy in the city was the Municipal Archaeological Museum Camil Visedo i Molto, a project of Javier Feduchi
Benlliure that transformed the Old Town Hall of Alcoy to house the showrooms and offices of the Museum of Archeology.

At the same time the urbanization and infrastructure works of the historic center were executed. Concern for the center became a priority when it was found that the potable water network had losses of more than onethird of the water flow, with the danger that it posed to the stability of the land on which the houses of the historical Center stood. For this reason, in addition to the renovation of roads, sidewalks, scuppers, tree grates, benches, litter bins and lampposts (Figure 3), a subterranean network of galleries was built to organize the urban services of water, electricity, sewers and rainwater. Only the telephone company did not agree to share that location with the other services and the phone network was arranged on the vault of the gallery.

These works consolidated the trust in the architecture as a catalyst of the desires and the individual efforts of all the actors involved. In fact it seemed that from a very different point of departure the goal to be achieved, the renewal of the city, could be read as a common desire that was being introduced collectively 
in the society, with real advantages for a large sector of the population.

After defining the areas in need of intervention, Mayor Jose Sanus proposes to the Generalitat Valenciana to summon a group of national and international architects of recognized professional background to undertake the projects of revitalization of the historic center. The debate on the historic city was at that time being developed by the most committed theoreticians of the Italian schools and by the most active urban planners such as the Porto school with Alvaro Siza as the most visible head and those of the urban planning laboratory of the UPB directed by Manuel de Solà-Morales. Also the urban proposal of Alan Colquhoun and John Miller in Cavendish Road shows another contemporary approach to the work on the city that also coud be rehearsed in Alcoy. With the fresh contribution of their experiences on the city, the participating architects discussed in different sessions in the City Hall the rough nature of sewing the deteriorated historical centers as a current issue that the European cities must confront in their many facets.

\section{The ARA plan}

The ARA plan (Architecture and Rehabilitation in Alcoy) was finally presented in 1991 (figure 2) emerging as a mature vision in the european line of complete urban projects on specific areas of the city in order to move away from the rigidity and formal indefinition of a General Plan. The projects were framed in three groups: periphery, edges of the historical center and interior areas. Within this classification parks, slopes, river beds and gardens, public and private housing, and institutional buildings were to be found.

The architecture works were published in 1992 in the Lotus magazine n. 71 dedicated to other urban approaches such as the Nexus World operation in Fukuoka and the planning of Dudok for Hilversum. The five projects exposed, La Riba, Portal de Riquer, Buidaoli, Beniata and Sang were the visible face of the ARA plan since the personal production of its authors was the guarantee that the Administration of the Generalitat needed to trust in the plan.

Beyond the question of whether to subordinate to a coordinating authority or to enjoy individual freedom of action, this general architectural vision was made from the autonomy of each project whose common link was to build a city with a strong character of unity. If we admit that the architect's concern is that his projects must have validity to exist, this objective is simpler when it is framed within an understanding or common plan in which architecture must face the updating of the inheritance received in the contemporary world. This property of architecture of becoming a truth in progress needs a thorough recognition of the territorial and urban boundary conditions of the project as well as the economic agents that render it possible. The ARA plan was to coordinate not only public investment in institutional and housing projects but also the inclusion of consolidated real estate developers who should understand and accept the new way of approaching the awakening of the city as a complex collective and spiritual creation of the civilization of which they are part.

Parks and gardens

Except that of Batoi, the parks were raised in the study of Vicente Vidal and Luis Armiño. They all had a high degree of difficulty in their execution due to the pronounced topographical mark of the peripheral areas of Alcoy.

Batoi park, with an area of 5.3 hectares, was designed to arrange the access from Banyeres road and link the most peripheral district of Alcoy with the west of the city integrating the limits of the Collao football field. The architects involved were Vicente Alcácer, Luis Casado, Vicente Colomer, Javier Soriano, Fernando Ricart and Arturo Sanz.

Romeral park, designed by architect Francisco Picó Silvestre, was intended to be not only a provision of a green area of 6.4 hectares for the neighborhood of Santa Rosa but also, in a more ambitious bet, a extension of the teaching facilities of the Romeral school. After more than twenty years of intensive use it still maintains the freshness of this gentle transition between the classrooms and nature.

Viaduct park. Architects Jose Cabanes and Margarita Valor built not only a linear park 


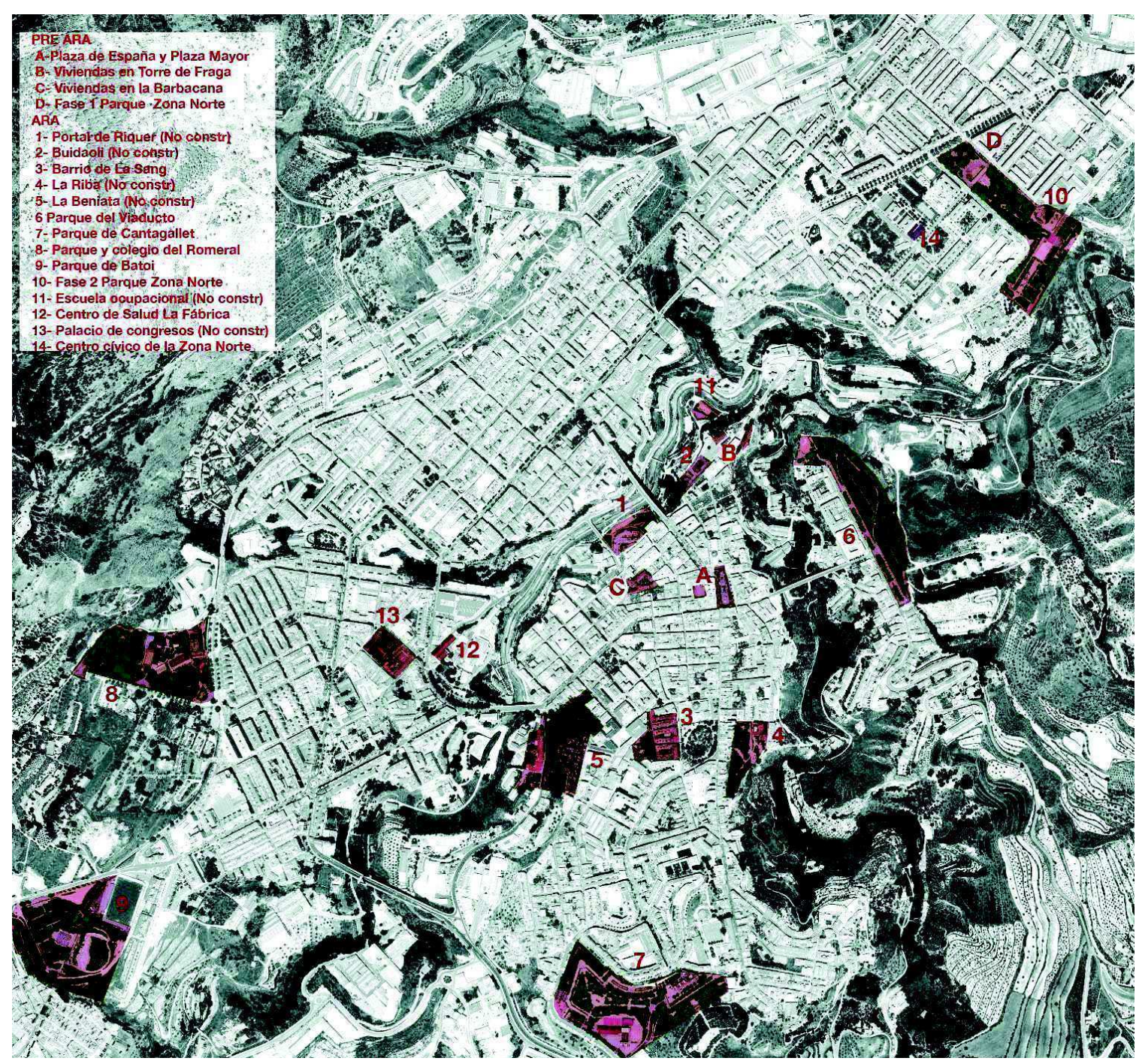

Figure 2.

Location of the ARA plan projects and the previous ones. OVVV

of 4.2 hectares on the spur of the slopes that fall on to the rivers Molinar and Serpis but consolidated those slopes and edges that had been sliding towards the riverbed continuously.

Cantagallet park, designed by architect Javier Pérez Igualada, consolidated and urbanised 6.2 hectares of the highest area of Alcoy in its southern access embracing the institute Pare Vitoria and ordering vacant spaces for a future rational disposition of buildings.

Housing projects.

Historic center PERI. With even a greater importance than the projects of the ARA plan, in 1989 the Special Plan of Interior Reform (PERI) of the Old Town was elaborated to be able to regulate the interventions and give coherence to all the urban fabric of Raval Vell and Raval Nou. This plan, designed by Carlos Meri Cucart, was a silent and highly ambitious proposal to regulate and clean up the historic plot. It contemplated a reduction of the buildability because it subtracted depth in order to eliminate excess of interior volumes and liberate interior space of the blocks. The lost surface could be recovered by the proprietosr elevating the height to courtyard to the same height of the cornice. In spite of the rational clarity that the drawings of sections, elevations and volumetries showed, the plan was rejected by the neighbors and proprietors since it was shown to public light.

The only project that was built was 


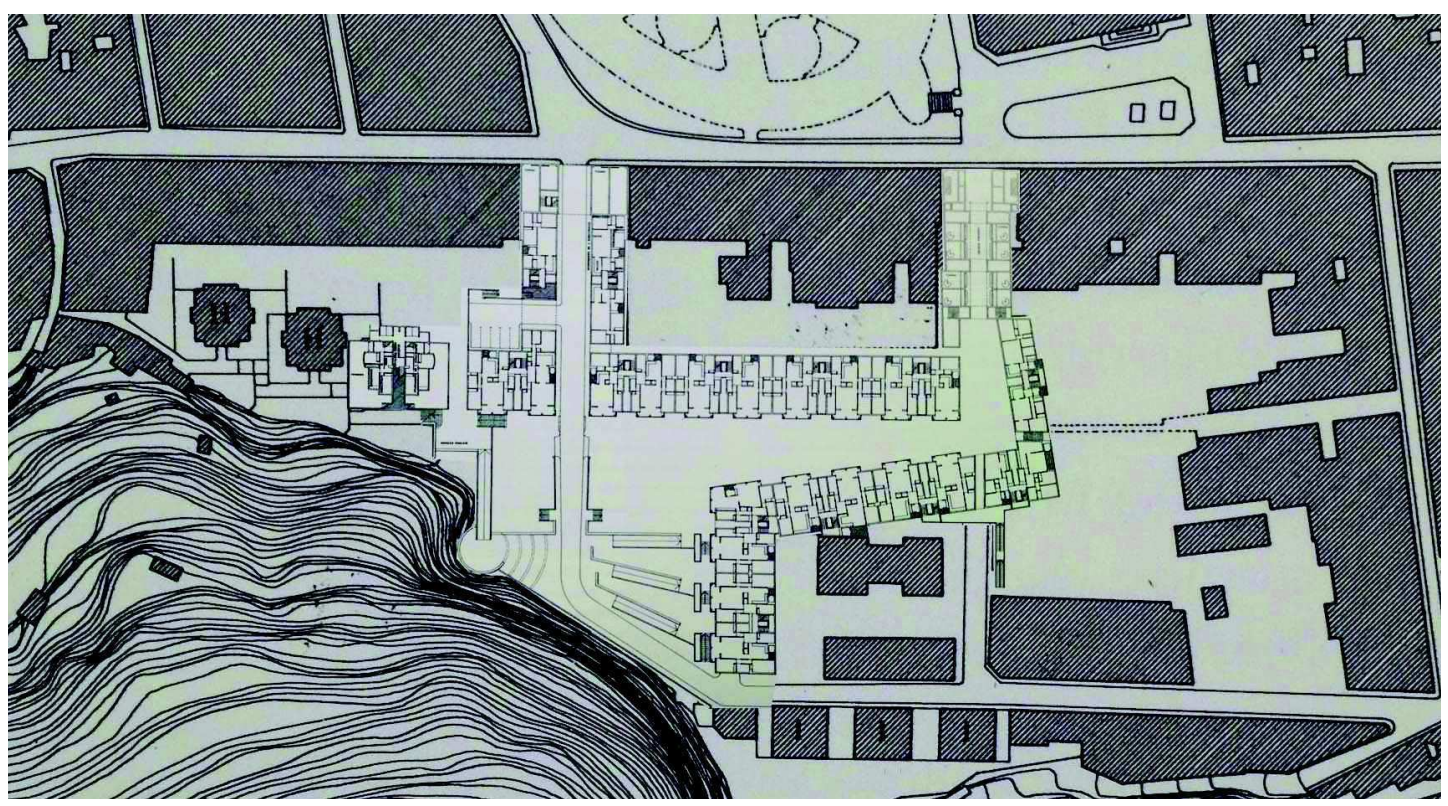

Figure 3.

First floor plan of La Riba project, by Colquhoun and Miller Partners.

the neighborhood of La Sang through the Valencian Institute of Housing (IVVSA). The other proposals did not achieve the enthusiasm of the public and private agents that should promote it.

La Beniata. This project of the Milanese architects Renato Rozzi and Carlo Carozzi wanted to bring together the wooded mass of the back gardens of the patrician houses that had been built in the 19th century and were becoming institutions. Slopes that suffered continuous landslides had to be consolidated and the housing volumes proposed the connection between the low area served by Alicante street and the upper level garden.

La Riba. The Riba area comprises the land between the bourgeois buildings of San Nicolas Street and the slopes of the Molinar River. This area was prompted by interests to promote housing so the the study of Alan Colquhoun and John Miller prepared a preliminary project that echoed those interests offering a high density building. Colquhoun preferred a more propositional and flexible strategy for a truly contemporary project, so he disengaged himself after his visit to the place. There was no longer any possibility of changing course since the private promoters had a great greediness for edificability (Figure 3).

Buidaoli. Architect Francesco Venezia had published a museum in the magazine
Casabella and, through that first work, he was invited to participate with a project that had to solve the elevation to the river Barxell from the left side of Saint George's bridge, just as Alvaro Siza solved the right side in the Portal de Riquer. The project extracted from the Italian Tendenza a compositional consequence of the elevation of Saint George's bridge and introduced an intensive parking program, as well as a complex operation of emptying and consolidating the limit of the historical city with elevated platforms like squares that had residential buildings on top. (Figure 4)

Portalde Riquer. This proposal by Alvaro Siza was the one that had more odds to become real due to a strategy of specific little interventions on the ruined buildings linked to the wall that put in value the volumetric ensemble with the rest of the wall that has a residential use. Siza never wanted to eliminate the masses on the walls as they weight stabilized the slopes. The project aims to preserve the walls because they are modest walls that were never thought beyond their use as a limit to regulate the taxes for goods entering the town. The door of the wall maintained the most primitive and more current version that is the ascending baroque perspective. Those old towers, edged and fenestrated, that emerge from the sides of the river Riquer or Barxell are the compositive base that Siza shows like an architectural material 


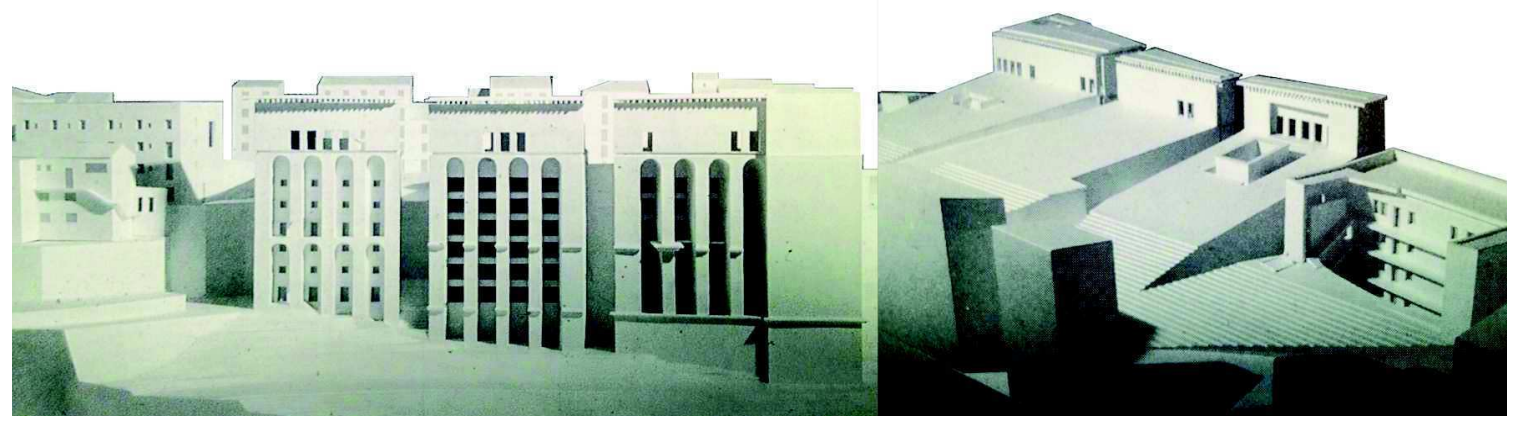

Figure 4.

Buidaoli model, by Francesco Venezia.

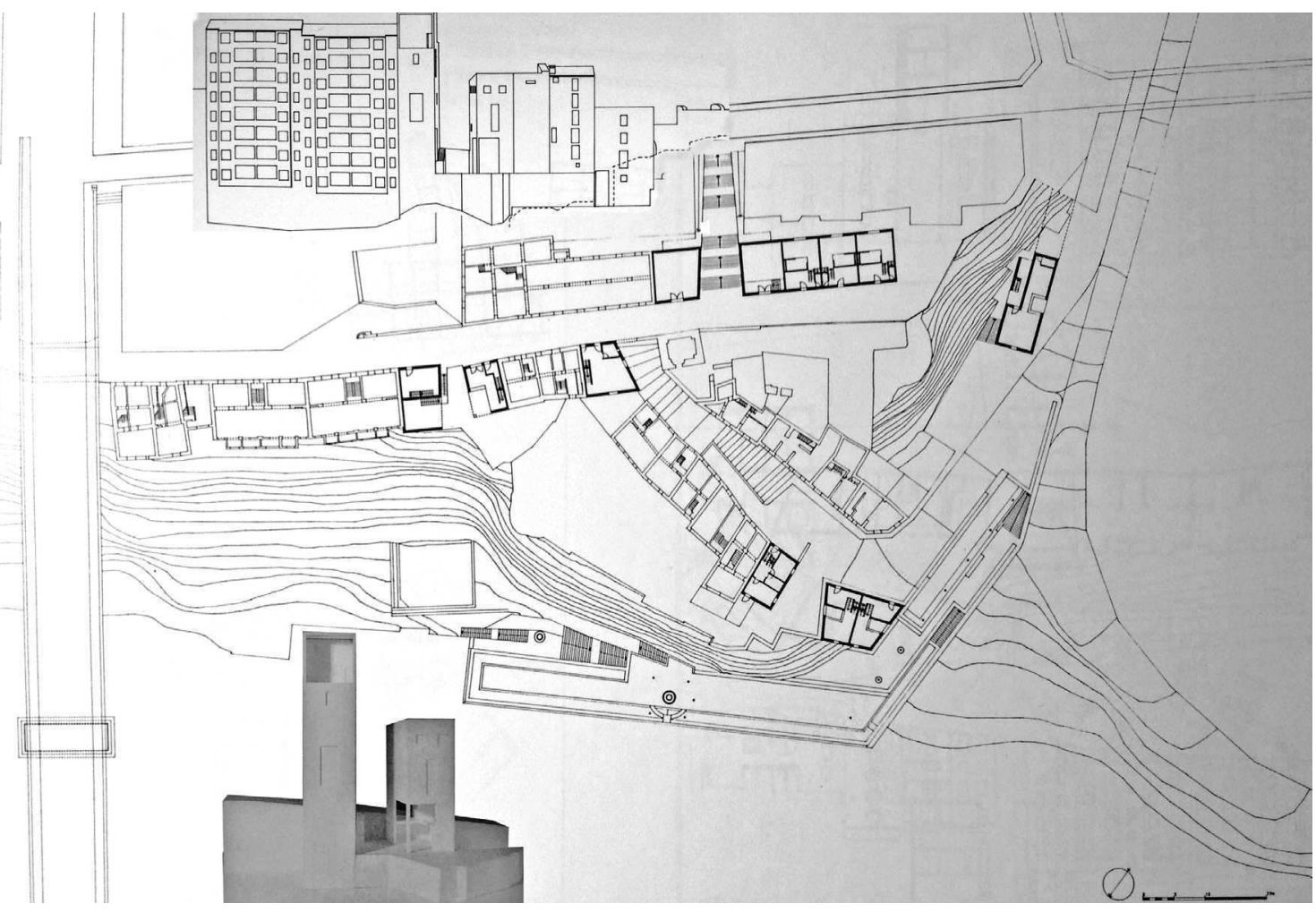

Figure 5.

Plan and Model of Portal de Riquer, by Alvaro Siza

rescued and put in a contemporary value. Only the patching and consolidation of the hillsides was carried out. (Figure 5).

La Sang. The project was developed simultaneously between Alcoy and Barcelona by Manuel de Solà-Morales, Vicente Vidal Vidal and Juan Lorenzo in 1992 (Figure 8). It is the only legacy of the ARA plan that has had the repercussion once imagined as it got the FAD prize of architecture of 1999 . The project went through the difficulties of the licitation with a reckless budget low of $30 \%$, of the bankrupt of the building company and the abandonment of the work during three years (Figure 6)
The propositional value of the Sang project assumed the historical memory of the working class neighborhood and the current urban reality. These principles were based on the preservation of the pedestrian streets, the evolution of the turbine stairs of the ruined previous houses, the acceptance of the car's servitude with the parking lots under construction, the mixing of residential use with commercial activity, the constructive restriction to two single window modules, the freedom of pure visual composition of the elevations, the acceptance of the internal gardens and its communication with the general garden as well 


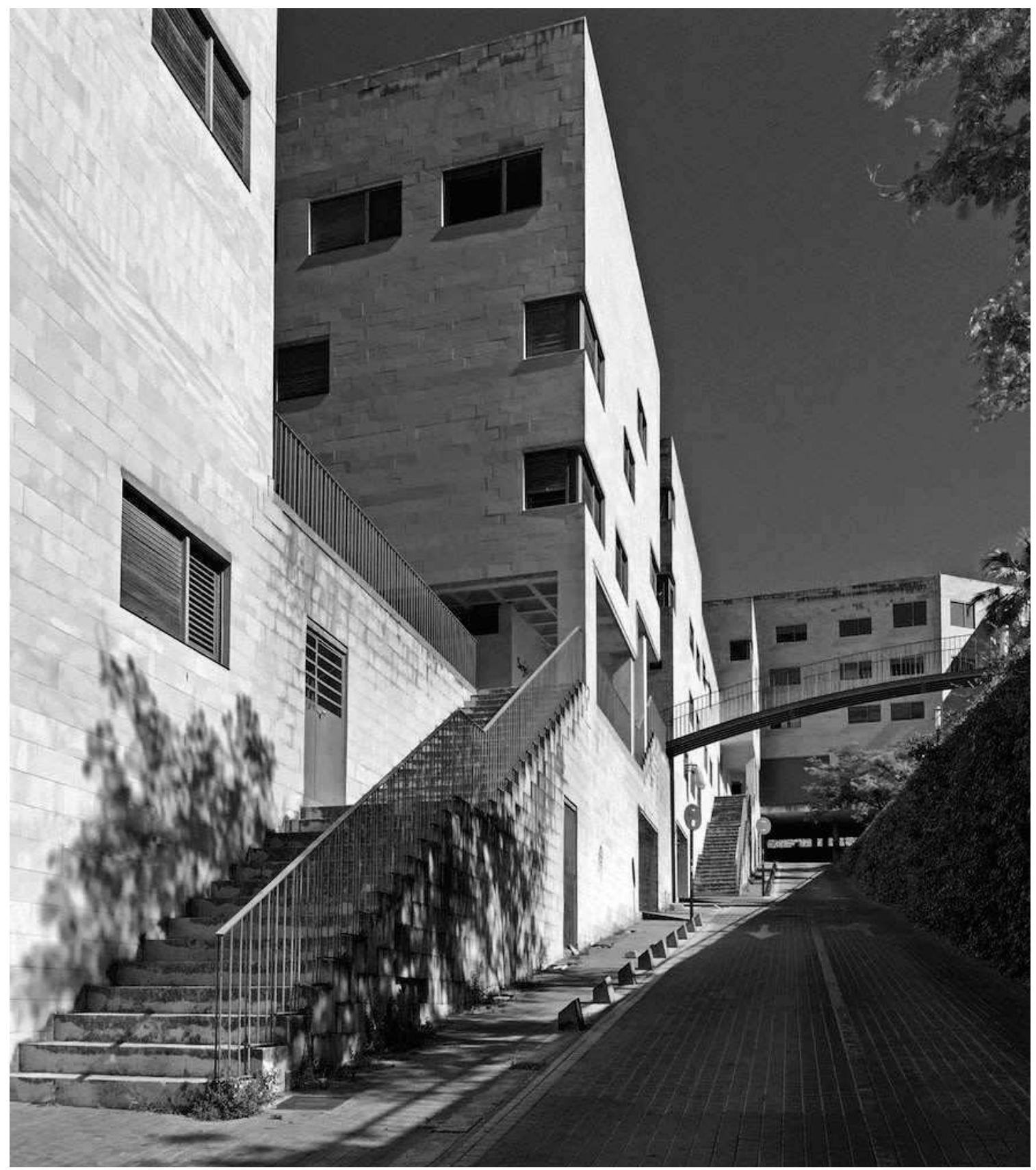

Figure 6.

View of La Sang ramp, in the neighborhood of La Sang, by Manuel de Solà-Morales

as the conservation of the mass character of the construction in Saint Matthew Street.

For the coherence of this approach there can be no interference between the access road to the garages and the road inherited from pedestrian streets and commercial streets. All these reasons gave rise to the audacious solution of opening the ramp of La Sang, that with a $14 \%$ of slope, connected Gurugú street with the entrances to the garages and, through a secondary ramp, with Sant Domènech commercial street.

Failure to carry out the rehabilitation project on Saint Matthew Street rendered hopeless the elusive principle of completeness pursued. No longer will the mixture between the solidity of the old restored buildings and the robustness of the new dwellings be perceived. The defense of the city's heritage is not only to keep the buildings protected but to improve or preserve 
the real quality of the manufactured ones that build their streets and that are the decantation of the work and life of the ancestors who inhabited those buildings. It is not a question of defending an inbred iconic conservation that only appreciates the last thin layer of what the eye does not see, but of claiming the rough effort of the construction and its ability to collect the witness of time by invoking its memory with the honesty of touch, either by hand or by the experienced eye.

With the shift of municipal government the houses of great typological uniformity that formed Saint Matthew Street were demolished and sold to the local promoters. This explains the emergence of the chamfers and the low quality of the façade material, provoking the sensation of a rough theatrical stage and destroying the perception of solidity of the volumes and of the sockets of existing ashlars from century XIX. This banal solution mutilated the complex urban operation of La Sang and although, over time, the loss of quality is masked by the distraction of everyday life, an explanation must be given because, as Manuel de SolàMorales said, restoration and rebuilding are different terms of the same problem.

Institutional projects.

Romeral School. In operation since 1992 the school was projected in 1986 by Vicente Vidal Vidal and Luis Alonso de Armiño. It is inserted in the park of the same name and configures through its southeastern limit the north ring that links the neighborhood of Batoy with the Uxola. The games court was set on top of the tank of water that serves the neighbourhood.

Francisco Laporta Sportscenter. Architects Vicente Colomer, Luis Casado and Vicente Alcácer ordered the accesses to the sports area and covered several tracks of game inside a expressive and sharp volume

La Fábrica Health Center. Again Colomer, Casado and Alcácer reconverted the former factory of Bernabéu in a healthcare center that's been intensively used since then.

The Font Roja (Red Fountain). The old ruined hotel and the chapel of the Font Roja were rehabilitated with a project of Carlos Meri Cucart. The chapel was conserved and the building would host an institute of the nature to study the botany, fauna and geology. The emergence of its clean and edged volume perpendicular to the slope of the mountain is affirmed with a fascade of Almorquí stone that modulates the fenestration and was used as a formwork in the reinforcement of the old concrete walls en masse.

The Professional School. This non-built project of Vicente Vidal and Luis Armiño reused the ashlar walls of the recently burned factory of tacos of the river Barxell to house a center of professional retraining of adults in unemployed labor situation.

The Auditorium and Palace of Congresses. The unbuilt project of Javier Feduchi Benlliure was a more complex cultural center and occupied a block of the metallurgical industry where had been the sections of foundry, forges, boiler, lathes and warehouses. The shift of autonomic government replaced it by the rehabilitation of the old Calderón theater.

Civic Center of the North Zone. This work by Carlos Meri is a neighborhood facility that integrates diverse social groups in a clean building of stone and marble.

Plaza de España. In 1992, promoted from the Generalitat, Santiago Calatrava arrived to remodel the Plaza de España with a project that was adhered to the ARA Plan. In addition to resurfacing the whole square maintaining the previous alignments, the project emptied the central tray of the square and built a subterranean exhibition room lit up through the roof. The budget exceeded more than thirty times the cost of the previous remodeling of the square (of 1982) and time proved that it became an unexpected end of the ARA plan

\section{Behind the scene of the urban form}

In spite of the mistakes, all the efforts, means and wills committed deserve attention. From the experience transmitted by the interventions in Bologna, the thesis defended by the local government in the regeneration of the city was the acquisition of lots to avoid speculation in the places where it was going to invest. This made it possible to complete the operation of public parks, leaving some building areas for other uses, such as educational or public housing. However, it did not channel private promotion 
to the places that needed restauration as local developers continued to build on their property lots where they could achieve higher capital gains. After a methodical acquisitive work the ARA projects had municipal land ownership to provide administrative coverage and coherence of action to the proposals. Within the consolidated fabric, once the streets of the historic center were updated with the galleries of urban services, the PERI was the instrument to regulate the interventions conserving the external envelope and releasing the inner space of the block.

The experience of the urban interventions in Alcoy reveals two modus operandi acting on the city, one strong and the other weak, and that they face each other in their antagonism or cooperate to complement each other. The strong one which is responsible for the shape and disposition of the masses, and the weak one is manifested in the intention and clarity of the architectural solutions. Despite acting on the urban medium with seemingly autonomous objectives, they need to cooperate in order to complement its various scales of action and assert with craftmaship and coherence the successive layers that make up the city.

The strong interaction pursues the transformation and growth in urban areas and does not stop to reflect on the historical memory or on the quality of the urban spaces or of the new buildings. The economic engine that drives the growth of the city is the necessity, but at the same time is a golden opportunity whose flashes are the claims of wealth, the pretension of status, or the anxiety for recognition. Individuals not particularly sensitive to the sense of citizenship channel their economic empowerment towards achieving their personal interests disguised under the collective interest and, therefore, their powerful transference to the urban scale produces banal solutions that the city assumes withot criticism.

By contrast the weak interaction is sensitive to the urban environment and housing as they are appropriate spaces that the human being needs for the balance of his identity. Therefore it acts slowly and slightly, driven by that argentiferous sand of beauty in which the architect strives hard at his work of finding the formal coherence, reconverting destroyed or alienating vacant spaces throughout the city in areas with quality for coexistence, whatever anonymous the life of its interpreters can be. However it can not satisfy the collective interest of everybody, but rather a fraction, because its scale is that of the intrinsic order of housing and public spaces whose use is linked to something that has no mercantile exchange. Thus, by producing a material without revenue we can not associate the weak interaction to the growth of the city, but to its improvement.

The case study of the ARA plan shows us that when these forces no longer act separately and truly cooperate within the limits of their respective scales is when the collective interest makes sense. In an advanced civilization degree it is when the individual becomes his own antagonist and draws away his personal interest in favour of a general necessity becoming a citizen and identifying himself with his polis. A city whose growth and continous transformation is carried out in response to these two forces, will move away from the banality of the urban form and will approach to the concinnitas, ie, the orderly balance of the different layers of consistency that the works of architecture demand through criteria of truth.

\section{References}

Alcoi de Fil de Vint. Arquitectura y Rehabilitación de Alcoi. Generalitat Valenciana. Conselleria d'Obres Públiques, Urbanisme i Transports. Mostra MarzoAbril 1991.

Cervellati, Pier Luigi and Scannavini, Roberto. Bolonia. Política y metodología de la restauración de centros históricos. Colección Materiales de la ciudad. Editorial Gustavo Gili. Barcelona 1976.

de Solà-Morales, Manuel (1992) Il nucleo urbano antico come categoria di progetto. Il quartiere di La Sang. Lotus 71. Lotus international. Rivista trimestrale di architettura. Electa. 86

Vidal Vidal, Vicente M. (1992) Il Piano Ara di Alcoy. Descrizione come premessa. Lotus 71. Lotus international. Rivista trimestrale di architettura. Electa.76 